\title{
The use of spirometry testing prior to cardiac surgery may impact the Society of Thoracic Surgeons risk prediction score: A prospective study in a cohort of patients at high risk for chronic lung disease
}

\author{
Niv Ad, MD, ${ }^{\mathrm{a}}$ Linda Henry, PhD, RN, ${ }^{\mathrm{a}}$ Linda Halpin, RN, MSN, ${ }^{\mathrm{a}}$ Sharon Hunt, MBA, ${ }^{\mathrm{a}}$ Scott Barnett, PhD, \\ Pamela Crippen, RN, ANP, ${ }^{a}$ Susan de Bullet, FNP, BC, ${ }^{a}$ and James Lamberti, MD ${ }^{\mathrm{b}}$
}

\begin{abstract}
Objectives: Chronic lung disease is a significant comorbidity in patients undergoing cardiac surgery. Chronic lung disease is currently being classified and reported to the Society of Thoracic Surgeons database by using either clinical interview or spirometric testing. We sought to compare the chronic lung disease classification captured by the 2 methods.
\end{abstract}

\begin{abstract}
Methods: We performed a prospectively designed study in which patients presenting for cardiac surgery, excluding emergent patients, were screened for a history of asthma, a history of 10 or more pack-years of smoking, a persistent cough, and the use of oxygen. Each selected patient underwent spirometry. The presence and severity of chronic lung disease was coded per Society of Thoracic Surgeons guidelines by using the 2 methods of clinical report and spirometric results. The chronic lung disease classifications were compared, and differences were determined by using concordance and discordance rates. The results were then used to construct Society of Thoracic Surgeons-predicted risk models.
\end{abstract}

Results: The discordant rate was $39.1 \%$, with underestimation of the severity of chronic lung disease in $94 \%$ of misclassified patients. This affected the Society of Thoracic Surgeons-predicted risk models for prolonged ventilation, morbidity/mortality, and mortality by increasing the predicted risk when spirometry was used for morbidity/mortality by an average of $1.5 \pm 1.2$ percentage points $(P<.001)$ and prolonged ventilation time by an average of $1.3 \pm 1.4$ percentage points $(P<.001)$.

Conclusion: The use of patient history for symptoms, medication, and/or oxygen use as the only method to determine chronic lung disease for this subgroup of patients led to underreporting of chronic lung disease and underestimation of the risk for adverse outcomes. Therefore data submission to the Society of Thoracic Surgeons database should be designed to capture and correct for potential bias in the definition of chronic lung disease because the rate of spirometry in different centers in defining chronic lung disease is not regulated. ( $\mathrm{J}$ Thorac Cardiovasc Surg 2010;139:686-91)

Chronic obstructive pulmonary disease (COPD) is a leading cause of morbidity and mortality in the United States ${ }^{1}$ and is often underdiagnosed not only in its early stages but also when there is severe impairment of lung function. The diagnosis of COPD or chronic lung disease (CLD) historically has depended on the presence of symptoms. Recent guidelines for the diagnosis of pulmonary disease use lung function measurements to diagnose and classify disease severity. ${ }^{2-4}$ Unfortunately, lung function measurements are infrequently performed by primary care physicians. During

From the Department of Cardiac Surgery Research, ${ }^{\mathrm{a}}$ Inova Heart and Vascular Institute, and the Department of Medicine, ${ }^{\mathrm{b}}$ Inova Fairfax Hospital, Falls Church, Va.

Disclosures: None.

Received for publication Feb 5, 2009; revisions received Sept 9, 2009; accepted for publication Oct 5, 2009; available ahead of print Dec 11, 2009.

Address for reprints: Niv Ad, MD, Cardiac Surgery, Inova Heart and Vascular Institute, 3300 Gallows Rd, Suite 109 B, Falls Church, VA 22042 (E-mail: Niv.Ad@ inova.org).

$0022-5223 / \$ 36.00$

Copyright (c) 2010 by The American Association for Thoracic Surgery doi:10.1016/j.jtcvs.2009.10.010 the year 2000, an estimated 10 million adults in the United States reported "physician-diagnosed COPD.,"4,5 A contemporaneous survey using lung function measurements resulted in a prevalence estimate of 23.6 million adults with COPD. ${ }^{6,7}$

Because cigarette smoking is a shared risk for cardiovascular and pulmonary disease, cardiac surgery is often performed on subjects with lung disease. Several reports have determined that the incidence of CLD in patients undergoing coronary artery bypass grafting can range from $4 \%$ to $27 \%$. More importantly, CLD is recognized as a significant risk factor for mortality and morbidity in patients undergoing cardiac surgery. ${ }^{8-11}$ Data obtained from spirometry provide information beyond the diagnosis of CLD. A large population-based study found that even small decrements in lung function in a restrictive pattern can be associated with underlying heart disease and are associated with an increased risk of death (hazard ratio, $1.7 ; 95 \%$ confidence interval, 1.4-2.0). ${ }^{12}$

The Society of Thoracic Surgeons' (STS) risk algorithms for determining 30-day operative mortality and morbidity risk and prolonged ventilation for patients undergoing cardiac surgery do not require spirometry to define the 


\section{Abbreviations and Acronyms \\ ATS = American Thoracic Society \\ CLD $=$ chronic lung disease \\ $\mathrm{COPD}=$ chronic obstructive pulmonary disease \\ ERS = European Respiratory Society \\ $\mathrm{FEV}_{1}=$ forced expiratory volume in 1 second \\ $\mathrm{FVC}=$ forced vital capacity[0] \\ STS = Society of Thoracic Surgeons}

presence, severity, or both of CLD. In general, because there is a gross underuse of spirometry, it is likely that across centers submitting data to the STS on the rate and severity of CLD, their respective reports are based on different methods of assessment and use of spirometry. We found that before this study less than $2 \%$ of our patients underwent spirometric testing before surgical intervention, and we assume other centers reporting data to the STS will have similar findings. Therefore assessment of CLD is vital to accurately predict expected outcomes in patients undergoing cardiac surgery, especially in the new era in which the prediction models of outcomes are so thoroughly assessed by the different organizations.

The purposes of the study were (1) to determine whether preoperative spirometric measures provide a better parameter in identifying the presence, severity, or both of CLD according to the STS definition compared with an assessment that is dependent on patient self-report for symptoms, medication, and/or home oxygen therapy; (2) to determine whether the use of spirometry in the identification of CLD has an effect on the STS-predicted risk models for prolonged ventilation, mortality, and morbidity; and (3) to determine whether our findings justify a review of the current method of capturing CLD data and a better control of the different methods used in identifying and classifying CLD and its respective potential bias on the STS risk score.

\section{MATERIALS AND METHODS \\ Design}

This was a prospective study. The intent was to "case find" patients who were at high risk for having lung disease; therefore each patient who presented for cardiac surgery, excluding emergent patients, were screened for a history of asthma, history of 10 pack-years or more of smoking, and/or a persistent cough (a cough lasting $\geq 4$ weeks). The study was reviewed and approved by our institutional review board.

After a patient was identified as meeting the inclusion criteria, spirometry was performed before surgical intervention. The spirometric testing was administered under the American Thoracic Society (ATS) and European Respiratory Society (ERS) standard guidelines for spirometric testing. ${ }^{2,3,13,14}$ The spirometric results were reviewed by a board-certified pulmonologist after first coding patients based on their self-report of medication, oxygen use, or both. The pulmonologist then recoded the patient's CLD, if any, by using the spirometric results according to the STS guidelines. The data from each CLD classification were compared. Other patient variables collected included age, sex, type of operation, length of hospital and intensive care unit stay, time to extubation, and postoperative complications. These were collected from the hospital's local inpatient STS database. In addition, patients were excluded from the analysis if their spirometric results were considered uninterruptible, as defined by the ATS/ERS task force. ${ }^{2,3,13,14}$

\section{Clinical Definitions}

Spirometry is the most common, widely available, and reproducible pulmonary function test that measures the volume of air inhaled and exhaled from the lungs over time. ${ }^{2,3,13,14}$ Two machines were used to assess spirometric results before surgical intervention: inpatient (SpiroPro; SensorMedics, Yorba Linda, Calif) and outpatient (Puritan Bennett Renaissance II; Puritan Bennett, Boulder, Colo). Both machines met the ATS/ERS standards. ${ }^{2,3,13,14}$ Spirometric testing was performed within 2 weeks of surgical intervention (median, 2.0 days).

CLD according to the STS standards was staged on the following definitions: (1) none, no medications or forced expiratory volume in 1 second $\left(\mathrm{FEV}_{1}\right)$ greater than $75 \%$ of predicted value; (2) mild, patient taking chronic inhaled or oral bronchodilator therapy or $\mathrm{FEV}_{1} 60 \%$ to $75 \%$ of percent predicted value; (3) moderate, patient taking chronic steroid therapy or $\mathrm{FEV}_{1}$ $50 \%$ to $59 \%$ of percent predicted value; or (4) severe, home oxygen or room air $\mathrm{Po}_{2}$ of less than 60 or room air $\mathrm{pCO}_{2}$ of greater than 50 or $\mathrm{FEV}_{1}$ less than $50 \%$ of percent predicted value. ${ }^{15-17}$

\section{Sample Size}

The total number of patients required for the study to have a nominal power of $80 \%$, a test proposition of $20 \%$, and an underlying undercoding prevalence of $10 \%$ was 294 . However, a preliminary analysis demonstrated that the underreporting of CLD by using clinical definitions without spirometry was greater than $40 \%$, which would require a sample size of 50 or more to retain a nominal power of $80 \%$.

\section{Statistical Analysis}

Continuous data are presented as means \pm standard deviations. Categorical data are presented as frequencies and percentages. Statistical comparisons were accomplished by means of 1-way analysis of variance, the $\chi^{2}$ test, or the Fisher's exact test, where appropriate. The rate of misclassification was determined by using concordance and discordance rates (referent variant analysis). Lastly, after spirometric results were obtained, predicted STS risks models for prolonged ventilation, morbidity/mortality, and mortality for patients undergoing coronary artery bypass grafting surgery were subsequently recalculated with the new spirometry-designated classification. Both original STS-predicted risk models and recalculated models based on spirometric results were then compared and displayed. The STS risk model was developed and validated as a risk-adjustment methodology for the control of potential confounding variables. ${ }^{15-17}$ All analyses were conducted with SAS software (version 9.1; SAS Institute, Inc, Cary, NC).

\section{RESULTS}

From October 2007 to October 2008, 220 patients met the inclusion criteria for the study and represented $23.3 \%$ of the patients who were operated on by us using the heart-lung machine during this period. Patients were classified into groups based on their respective spirometric results. Table 1 displays the patients' demographics and clinical characteristics overall and by group. Regardless of classification, the average age was $64.9(\mathrm{SD}, 10.9)$ years, $78 \%$ of the patients were male, and $10 \%$ were current smokers. Patients in the severe group were significantly older ( $68 \pm 10.1$ years) and had a significant decrease in their $\mathrm{FEV}_{1}$ percent predicted values $(45.0 \%$ $\pm 13.1 \%$ ) when compared with the other groups. 
TABLE 1. Patient demographics and clinical characteristics by STS group (postspirometric classification)

\begin{tabular}{|c|c|c|c|c|c|c|}
\hline & $\begin{array}{l}\text { Total spirometry } \\
\text { group }(n=220)\end{array}$ & $\begin{array}{l}\text { No CLD } \\
(\mathrm{n}=\mathbf{1 0 3})\end{array}$ & $\begin{array}{l}\text { Mild CLD } \\
(\mathrm{n}=62)\end{array}$ & $\begin{array}{l}\text { Moderate CLD } \\
\quad(\mathbf{n}=\mathbf{2 1})\end{array}$ & $\begin{array}{l}\text { Severe CLD } \\
\quad(\mathbf{n}=\mathbf{2 8})\end{array}$ & $P$ value \\
\hline Age (y) & $64.5 \pm 10.9$ & $62.1 \pm 9.7$ & $66.9 \pm 12.1$ & $66.0 \pm 11.2$ & $68.0 \pm 10.1$ & .010 \\
\hline Ejection fraction $(\%)$ & $51.6 \pm 13.6$ & $53.7 \pm 12.4$ & $48.9 \pm 15.8$ & $49.8 \pm 14.7$ & $50.3 \pm 12.0$ & .145 \\
\hline Body mass index $\left(\mathrm{kg} / \mathrm{m}^{2}\right)$ & $29.2 \pm 6.0$ & $29.6 \pm 6.3$ & $28.4 \pm 5.3$ & $28.3 \pm 4.5$ & $29.4 \pm 7.0$ & .564 \\
\hline $\mathrm{FEV}_{1}(\%)$ & $75.3 \pm 24.5$ & $88.2 \pm 23.0$ & $72.4 \pm 25.0$ & $54.1 \pm 8.7$ & $45.0 \pm 13.1$ & $<.001$ \\
\hline FVC $(\%)$ & $84.3 \pm 46.4$ & $96.3 \pm 58.8$ & $82.4 \pm 32.3$ & $61.3 \pm 8.6$ & $64.3 \pm 20.9$ & .001 \\
\hline Male sex & $171(77.7)$ & $86(83.5)$ & $47(75.8)$ & $15(71.4)$ & $20(71.4)$ & .360 \\
\hline NYHA class (III or IV) & $47(21.4)$ & $13(12.6)$ & $17(27.4)$ & $7(33.3)$ & $9(32.1)$ & .914 \\
\hline Currently smoking & $22(10.0)$ & $2(1.9)$ & $4(6.4)$ & $3(14.3)$ & $1(3.6)$ & .086 \\
\hline Family history of CAD & $138(62.7)$ & $65(63.1)$ & $36(58.1)$ & $15(71.4)$ & $18(64.3)$ & .736 \\
\hline Diabetes & $74(33.8)$ & $30(29.1)$ & $20(32.2)$ & $6(28.6)$ & $12(42.8)$ & .572 \\
\hline History of renal failure & $5(2.3)$ & $3(2.9)$ & $1(1.6)$ & $1(4.8)$ & $0(0)$ & .686 \\
\hline CLD (severe) & $28(12.7)$ & $0(0)$ & $0(0)$ & $0(0)$ & $28(100)$ & $<.001$ \\
\hline CVA & $16(7.3)$ & $3(2.9)$ & $5(8.1)$ & $5(23.8)$ & $3(10.7)$ & .008 \\
\hline Myocardial infarction & $15(6.8)$ & $6(5.8)$ & $5(8.1)$ & $3(14.3)$ & $1(3.6)$ & .473 \\
\hline Hypercholesterolemia & $21(9.5)$ & $7(6.8)$ & $8(12.9)$ & $4(19.0)$ & $2(7.1)$ & .267 \\
\hline Hypertension & $175(79.5)$ & $79(76.7)$ & $49(79.0)$ & $17(80.9)$ & $24(85.7)$ & .772 \\
\hline Peripheral vascular disease & $39(17.7)$ & $14(13.6)$ & $14(22.6)$ & $3(14.3)$ & $7(25.0)$ & .339 \\
\hline Cerebrovascular disease & $36(16.4)$ & $10(9.7)$ & $13(21.0)$ & $8(38.1)$ & $4(14.3)$ & .008 \\
\hline Previous valve & $2(0.9)$ & $0(0)$ & $0(0)$ & $1(4.8)$ & $1(3.6)$ & .072 \\
\hline Previous CABG & $4(1.8)$ & $2(1.9)$ & $0(0)$ & $1(4.8)$ & $1(3.6)$ & .465 \\
\hline Elective & $98(44.5)$ & $45(43.7)$ & $33(53.2)$ & $7(33.3)$ & $10(35.7)$ & .278 \\
\hline
\end{tabular}

Values are presented as means (standard deviations) and numbers (percentages), where shown. Six patients were missing values. $S T S$, Society of Thoracic Surgeons; $C L D$, chronic lung disease; $F E V_{1}$, forced expiratory volume in 1 second; $F V C$, forced vital capacity; $N Y H A$, New York Heart Association; $C A D$, coronary artery disease; $C V A$, cerebrovascular accident; $C A B G$, coronary artery bypass grafting.

\section{Perioperative Complications}

The STS database guidebook definitions were used to determine perioperative complications. ${ }^{17}$ Twenty $(9.1 \%)$ patients had a prolonged ventilation time, $8(3.6 \%)$ patients had pneumonia, $68(30.9 \%)$ patients had lengths of stay greater than 7 days, and $3(1.4 \%)$ patients died within 30 days of surgical intervention. Statistically significant differences were noted for the following variables: transient stroke, prolonged ventilation time, pneumonia, length of stay greater than 7 days, 30-day mortality, and readmission at 30 days or less after the operation. However, the real clinical significance might need to be tested with a larger cohort of patients (Table 2).

\section{Spirometric Findings}

One hundred ninety-two patients had interpretable spirometric results. Seventy-five of the 192 patients were found to be misclassified/discordant, resulting in an overall discordant rate of $39.1 \%$. The severity of CLD was underestimated in $71(94.7 \%)$ of the 75 misclassified patients. Table 3 displays the number of patients misclassified for each category of CLD, as defined by the STS. More than $44 \%$ of the patients in the mild CLD category based on clinical evaluation were misclassified when the spirometric results were obtained.

Table 4 compares the STS-predicted risk models for prolonged ventilation, morbidity/mortality, and mortality with and without the use of spirometry. The predicted risk for any one of the 3 modeled complications was significantly higher when calculated with spirometry rather than clinical assessment for the standard STS definition. The greatest effect was observed for composite morbidity/mortality, with an average increase in predicted risk of $1.5 \pm 1.2(P<$ .001) percentage points when spirometric information was used. Clinical diagnosis also underestimated the risk of prolonged ventilation time by an average of $1.3 \pm 1.4(P<.001)$ percentage points (Figure 1).

\section{DISCUSSION}

In this study we set out to determine whether the use of spirometric measures in a subset of patients undergoing cardiac surgery before the surgical intervention would provide a better parameter in determining the presence, severity, or both of CLD when compared with clinical classification based on STS definitions for CLD. Our findings suggest there is a significant underestimation of the prevalence and severity of CLD when using the STS definitions without spirometry. The greatest disparity was seen among patients who would have been classified as having either no or mild disease when, in fact, severe disease was detected in more than $12 \%$ of these patients.

In addition, the purpose of this study was to determine the effect, if any, on the STS-predicted risk models for prolonged ventilation, mortality, and morbidity. We did find that the use of spirometry affected the aforementioned STS risk models. This study determined that the use of 
TABLE 2. Perioperative complication rates by STS group (postspirometric classification)

\begin{tabular}{|c|c|c|c|c|c|c|}
\hline & $\begin{array}{l}\text { Total spirometry } \\
\text { group }(n=220)\end{array}$ & $\begin{array}{l}\text { No CLD } \\
(\mathrm{n}=103)\end{array}$ & $\begin{array}{c}\text { Mild CLD } \\
(\mathrm{n}=62)\end{array}$ & $\begin{array}{c}\text { Moderate CLD } \\
\quad(\mathbf{n}=\mathbf{2 1})\end{array}$ & $\begin{array}{c}\text { Severe CLD } \\
(\mathbf{n}=\mathbf{2 8})\end{array}$ & $P$ value \\
\hline Transient stroke & $1(0.5)$ & $0(0)$ & $0(0)$ & $1(4.8)$ & $0(0)$ & .026 \\
\hline Permanent stroke & $4(1.8)$ & $2(1.9)$ & $1(1.6)$ & $0(0)$ & $0(0)$ & .820 \\
\hline Septicemia & $1(0.5)$ & $0(0)$ & $1(1.6)$ & $0(0)$ & $0(0)$ & .487 \\
\hline Mediastinitis & $1(0.5)$ & $0(0)$ & $0(0)$ & $0(0)$ & $1(3.6)$ & .083 \\
\hline Cardiac tamponade & $2(0.9)$ & $1(1.0)$ & $0(0)$ & $0(0)$ & $0(0)$ & .785 \\
\hline Prolonged ventilator time & $20(9.1)$ & $4(3.9)$ & $8(12.9)$ & $0(0)$ & $7(25.0)$ & .001 \\
\hline Pneumonia & $8(3.6)$ & $0(0.0)$ & $3(4.8)$ & $1(4.8)$ & $4(14.3)$ & .004 \\
\hline Renal failure & $15(6.8)$ & $5(4.8)$ & $6(9.7)$ & $1(4.8)$ & $2(7.1)$ & .664 \\
\hline Dialysis required & $3(1.4)$ & $1(1.0)$ & $1(1.6)$ & $0(8)$ & $1(3.6)$ & .707 \\
\hline Reoperation for bleeding & $2(0.9)$ & $0(0)$ & $1(1.6)$ & $1(4.8)$ & $0(0)$ & .184 \\
\hline Atrial fibrillation & $22(10.0)$ & $10(9.7)$ & $7(11.3)$ & $1(4.8)$ & $3(10.7)$ & .856 \\
\hline Length of stay $\geq 7 \mathrm{~d}$ & $68(30.9)$ & $18(17.4)$ & $21(33.9)$ & $10(47.6)$ & $17(60.7)$ & $<.001$ \\
\hline 30-d Mortality & $3(1.4)$ & $0(0)$ & $1(1.6)$ & $0(0)$ & $2(7.1)$ & .037 \\
\hline Readmission $\leq 30 \mathrm{~d}$ & $15(6.8)$ & $7(6.8)$ & $2(3.2)$ & $0(0)$ & $6(21.4)$ & .007 \\
\hline
\end{tabular}

STS, Society of Thoracic Surgeons; $C L D$, chronic lung disease.

spirometry in the risk models created an underreporting of the expected number of adverse outcomes to include death by $2 \%$ to $25 \%$ depending on the degree of CLD severity identified.

This underreporting suggests that the current STS method of defining CLD might not be adequate. Having the option of using a clinical diagnosis versus spirometry might not be enough because the STS currently does not provide models that incorporate clinical diagnosis-only or spirometry-only models. Therefore it is apparent that the STS needs to address how best to capture CLD data or adjust for the method used to identify CLD so that the STS-predicted risk models can be correctly calculated, applied, and interpreted for a given patient population and across cardiac surgery centers.
Furthermore, the correct calculation of the risk models carries significance beyond the immediate postoperative period of time. In this era of tying compensation to outcome, there is increased accountability for the health professional. Having correctly calculated predicted risk models can be imperative to the success of a cardiac surgery program. ${ }^{18,19}$

Another relevant concern we had in the design of our study was the increased cost associated with additional testing before surgical intervention, even a relatively small one. This was one reason why we designed the study to "case find" patients with a higher risk for CLD who most likely would benefit from early intervention, especially patients with severe disease. The true effect of early intervention on patients identified with a certain level of impairment

TABLE 3. Cross-tabulation of clinical versus spirometric assessment $(\mathbf{n}=192) *$

\begin{tabular}{|c|c|c|c|c|c|c|}
\hline & \multicolumn{6}{|c|}{ Spirometric assessment } \\
\hline & & No CLD & Mild CLD & Moderate CLD & Severe CLD & Total \\
\hline \multirow[t]{5}{*}{ Clinical assessment } & No CLD & 96 & 33 & 11 & 12 & 152 \\
\hline & Mild CLD & 2 & 20 & 5 & 9 & 36 \\
\hline & Moderate CLD & 1 & 0 & 0 & 1 & \\
\hline & Severe CLD & 0 & 1 & 0 & 1 & \\
\hline & Total & 99 & 54 & 16 & 23 & $192 *$ \\
\hline
\end{tabular}

Concordance rate: $60.9 \%,(117 / 192)$

Discordance rate: $39.1 \%$, $(75 / 192)$

Underestimation by STS definition: $94.6 \%(71 / 75)$

Overestimation by STS definition: $5.4 \%(4 / 75)$

Misclassification rate by prespirometric STS class

$\begin{array}{lrl}\text { No CLD } & 56 / 152 & (36.8 \%) \\ \text { Mild CLD } & 16 / 36 & (44.4 \%) \\ \text { Moderate CLD } & 2 / 2 & (100.0 \%) \\ \text { Severe CLD } & 1 / 2 & (50.0 \%)\end{array}$

*Twenty-eight patients were given diagnoses of "unknown” based on American Thoracic Society guidelines. CLD, Chronic lung disease; STS, Society of Thoracic Surgeons. 
TABLE 4. Average values for STS-predicted risk models with and without spirometry

\begin{tabular}{llcc}
\hline & & \multicolumn{2}{c}{$\begin{array}{c}\text { Total spirometry } \\
\text { group }(\mathbf{n}=\mathbf{1 9 2})\end{array}$} \\
\hline $\begin{array}{l}\text { Prolonged ventilation } \\
\text { time }\end{array}$ & STS without spirometry & $5.5 \pm 4.4$ & - \\
& & & \\
Mortality & STS with spirometry & $6.8 \pm 5.8$ & $P<.001$ \\
& STS without spirometry & $1.1 \pm 1.3$ & - \\
Morbidity/mortality & STS with spirometry & $1.3 \pm 1.8$ & $P<.001$ \\
& STS without spirometry & $8.9 \pm 6.1$ & - \\
& STS with spirometry & $10.4 \pm 7.3$ & $P<.001$ \\
\hline
\end{tabular}

STS, Society of Thoracic Surgeons.

requires a long-term clinical study, which was beyond the scope of this study. However, we did show that the use of spirometry is important when determining CLD in a subset of patients so that more in-depth assessment can take place.

A further area of exploration should focus on the consideration of using the ATS/ERS guidelines in determining CLD rather than the current definitions. A strength of the ATS/ERS guidelines is that they provide for 2 different types of ventilatory defects: obstructive and restrictive abnormalities. An obstructive abnormality is defined as an $\mathrm{FEV}_{1}$ /forced vital capacity (FVC) of less than the fifth percentile of the predicted value. A restrictive abnormality is defined as an FVC reduction to less than the fifth percentile of the predicted value and a normal $\mathrm{FEV}_{1} / \mathrm{FVC}$ ratio. ${ }^{14}$ Perhaps thought should be given to incorporating both $\mathrm{FEV}_{1}$ and $\mathrm{FVC}$, if not the diffusion capacity of the lung for carbon monoxide, when determining CLD. ${ }^{2,3,13,14}$

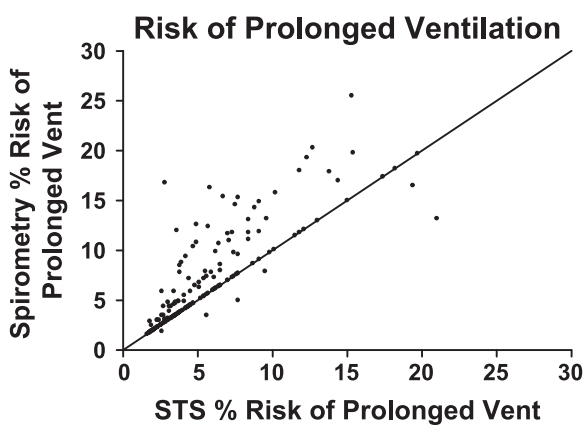

\section{Limitations of the Current Study and Analysis}

Spirometry was only performed in subjects with a history of asthma, a 10 pack-year or greater smoking history, or a chronic cough. By focusing only on this cohort of patients, we might have missed some patients with abnormal spirometric results. Also, restriction on the use of spirometry only might represent factors other than intrinsic pulmonary disease, such as neuromuscular weakness, congestive heart failure, pleural effusions, and obesity.

In addition, the study design (preselecting patients at a higher risk for CLD) might have a potential for work-up bias. Work-up bias was originally described by Ransohoff and Feinstein ${ }^{20}$ in the late 1970 s, when they wrote about inherent biases in diagnostic testing. More recently, Blackstone and Lauer, ${ }^{21}$ in their 2004 editorial for the Journal of Thoracic and Cardiovascular Surgery, discussed the treachery of work-up bias and the generalizability of investigators' findings. They described work-up bias as " ...occurs whenever a test is performed and a gold standard (reference) validation is not performed for each patient, and accuracy of the test is reported for only patients with reference validation." We did not correct for any bias that might be introduced in our findings.

\section{CONCLUSION}

The findings of this study suggest that the presence and severity of CLD might be significantly underreported in a cohort of patients $(\geq 10$ pack-year smoking history, asthma, or a persistent cough) when using only the STS definitions without spirometry. The underreporting/misclassification

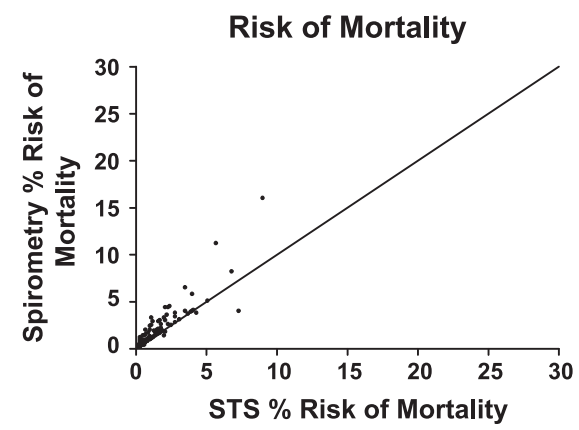

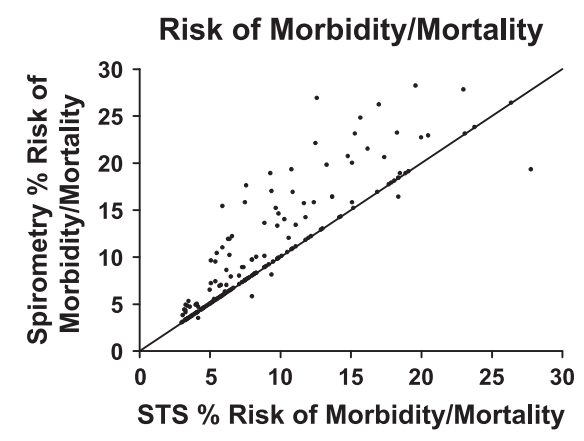

FIGURE 1. Clinical and spirometric comparison of the Society of Thoracic Surgeons-predicted risk models for prolonged ventilation time, mortality and morbidity, and operative mortality. 
led to a perceived decrease in the risk for adverse outcomes. This study found that when the STS definitions with spirometry were used to determine CLD, the predicted risk models for prolonged ventilation, morbidity/mortality, and mortality were significantly adversely changed. This adverse change can have a significant effect on composite risk stratification scoring for cardiac surgery programs. Consideration should be given to using spirometric testing when determining CLD in a cohort of patients. Further study should be undertaken to determine whether all patients presenting for cardiac surgery should undergo spirometry and how the STS should define, adjust for, or both the method used to identify CLD.

\section{References}

1. Mannino D. Chronic obstructive pulmonary disease: definition and epidemiology. Respir Care. 2003;48:1185-93.

2. Celli BR, MacNee W. ATS/ERS Task Force. Standards for the diagnosis and treatment of patients with COPD: a summary of the ATS/ERS position paper. Eur Respir J. 2004;23:932-46.

3. Gold Guidelines 2008. Global strategy for the diagnosis, management and prevention of COPD, Global Initiative for Chronic Obstructive Lung Disease (GOLD) 2008. Available at: http://www.goldcopd.org. Accessed Feb 2, 2008.

4. Mannino DM, Homa DM, Akinbami LJ, Ford ES, Redd SC. Chronic obstructive pulmonary disease surveillance-United States, 1971-2000. MMWR Surveill Summ. 2002;51:1-16.

5. Han MK, Kim MG, Mardon R, Renner P, Sullivan S, Diette GB, et al. Spirometry utilization for COPD: how do we measure up? Chest. 2007;132:403-9.

6. Kaminsky DA, Marcy TW, Bachand M, Irvin CG. Knowledge and use of office spirometry for the detection of chronic obstructive pulmonary disease by primary care physicians. Respir Care. 2005;50:1639-48.

7. Mannino DM, Gagnon RC, Petty TL, Lydick E. Obstructive lung disease and low lung function in adults in the United States: data from the National Health and Nutrition Examination Survey, 1988-1994. Arch Intern Med. 2000;160: 1683-9.

8. US Department of Health and Human Services. The consequences of smoking. A report by the Surgeon General. Atlanta, Ga: Department of Health and Human
Services, Centers of Disease Prevention and Health Promotion, Office of Smoking and Health; 2004. Available at: http://www.cdc.gov/tobacco/factsheets/ HealthEffectsofCigaretteSmoking_Factsheet.htm. Accessed December 22, 2008.

9. US Department of Health and Human Services. MMWR weekly: annual smoking attributable mortality, years of potential life lost, and economic costs-United States, 1995-1999. Department of Health and Human Services, Centers of Disease Prevention and Health Promotion, Office of Smoking and Health; 2002. Available at: http://www.cdc.gov/mmwr/preview/mmwrhtml/mm5114a2.htm. Accessed December 22, 2008

10. Leavitt BJ, Ross CS, Spence B, Surgeonor S, Olmstead EM, Clough RA, et al Long term survival of patients with chronic obstructive pulmonary disease undergoing coronary artery bypass surgery. Circulation. 2006;114(suppl):I430-4.

11. Gardner SC, Grunwald GK, Rumsfeld JS, Mackenzie T, Gao D, Perlin JB, et al Risk factors for intermediate term survival after coronary artery bypass grafting. Ann Thorac Surg. 2001;72:2033-7.

12. Mannino DM, Buist AS, Petty TL, Enright PL, Redd SC. Lung function and mortality in the United States: data from the First National Health and Nutrition Examination Survey followup study. Thorax. 2003;58:388-93.

13. Pellegrino R, et al. Series "ATS/ERS task force: Standardization of lung function testing" Number 5-interpretative strategies for lung function tests. Eur Respir J. 2005;26:948-968

14. Miller M, Hankinson J, Brusasco V, Burgos F, Casaburi R, Coates A, et al. Standardization of spirometry. Eur Respir J. 2005;26:319-38.

15. The Society of Thoracic Surgeons Adult Cardiac Surgery Database Training Manual, v2.61. Available at: http://www.sts.org/sections/stsnationaldatabase/datamanagers/ congenitalheartsurgerydb/taskforce/articles/trainingmanual2.61.html. Accessed March 4, 2009.

16. Society of Thoracic Surgeons' risk models. Available at: http://209.220.160.181/ STSWebRiskCalc261/STS $\% 20$ Web $\%$ 20Risk \% 20Calculator $\% 20$ Descriptor.pdf. Accessed March 5, 2009.

17. Shroyer AL, Coombs LP, Petersen ED, Eiken MC, DeLong ER, Chen A, et al. The Society of Thoracic Surgeons: 30 day operative mortality and morbidity risk models. Ann Thorac Surg. 2003;75:1856-65.

18. Halpin LD, Barnett SD, Henry LL, Choi E, Ad N. Public health reporting: the United States perspective. Semin Cardiothorac Vasc Anesth. 2008;12: 191-202.

19. Snyder L, Neubauer RL. Pay for performance principles that promote patient-centered care: an ethics manifesto. Ann Intern Med. 2007;147:792-4.

20. Ransohoff DF, Feinstein AR. Problems of spectrum and bias in evaluating the efficacy of diagnostic tests. N Engl J Med. 1978;2999:926-30.

21. Blackstone EH, Lauer MS. Caveat emptor: the treachery of work up bias. JThorac Cardiovasc Surg. 2004;128:341-4. 